\title{
Quantitative production of butenes from biomass-derived - valerolactone catalysed by hetero-atomic MFI zeolite
}

DOI:

10.1038/s41563-019-0562-6

\section{Document Version}

Accepted author manuscript

Link to publication record in Manchester Research Explorer

\section{Citation for published version (APA):}

Lin, L., Sheveleva, A., Silva, I. D., Parlett, C., Tang, Z., Liu, Y., Fan, M., Han, X., Carter, J., Tuna, F., Mcinnes, E., Cheng, Y., Daemen, L. L., Rudic, S., Ramirez-Cuesta, A. J., Tang, C. C., \& Yang, S. (2019). Quantitative production of butenes from biomass-derived -valerolactone catalysed by hetero-atomic MFI zeolite. Nature Materials, 19, 86-93. https://doi.org/10.1038/s41563-019-0562-6

\section{Published in:}

Nature Materials

\section{Citing this paper}

Please note that where the full-text provided on Manchester Research Explorer is the Author Accepted Manuscript or Proof version this may differ from the final Published version. If citing, it is advised that you check and use the publisher's definitive version.

\section{General rights}

Copyright and moral rights for the publications made accessible in the Research Explorer are retained by the authors and/or other copyright owners and it is a condition of accessing publications that users recognise and abide by the legal requirements associated with these rights.

\section{Takedown policy}

If you believe that this document breaches copyright please refer to the University of Manchester's Takedown Procedures [http://man.ac.uk/04Y6Bo] or contact uml.scholarlycommunications@manchester.ac.uk providing relevant details, so we can investigate your claim.

\section{OPEN ACCESS}




\section{Quantitative production of butenes from biomass-derived $\gamma$-valerolactone catalysed by hetero-atomic MFI zeolite}

Longfei Lin ${ }^{1}$, Alena M. Sheveleva ${ }^{1,2}$, Ivan da Silva ${ }^{3}$, Christopher M. A. Parlett ${ }^{4,5,6}$, Zhimou Tang ${ }^{7}$, Yueming Liu $^{7}$, Mengtian Fan ${ }^{1}$, Xue Han ${ }^{1}$, Joseph H. Carter ${ }^{1}$, Floriana Tuna ${ }^{1}$, Eric J. L. McInnes ${ }^{1}$, Yongqiang Cheng ${ }^{8}$, Luke L. Daemen ${ }^{8}$, Svemir Rudić ${ }^{3}$, Anibal J. Ramirez-Cuesta ${ }^{8}$, Chiu C. Tang ${ }^{6}$ and Sihai Yang ${ }^{1 *}$

1. School of Chemistry and Photon Science Institute, University of Manchester, Manchester, M13 9PL (UK)

2. International Tomography Centre SB RAS and Novosibirsk State University, Novosibirsk, 630090 (Russia)

3. ISIS Facility, STFC, Rutherford Appleton Laboratory, Chilton, Oxfordshire, OX11 0QX (UK)

4. School of Chemical Engineering and Analytical Science, University of Manchester, Manchester, M13 9PL (UK)

5. University of Manchester at Harwell, Diamond Light Source, Harwell Campus, Didcot, Oxfordshire, OX11 0DE (UK)

6. Diamond Light Source, Harwell Science and Innovation Campus, Didcot, Oxfordshire, OX11 0DE (UK)

7. Shanghai Key Laboratory of Green Chemistry and Chemical Processes, School of Chemistry and Molecular Engineering, East China Normal University, Shanghai, 200062 (China)

8. The Chemical and Engineering Materials Division (CEMD), Neutron Sciences Directorate, Oak Ridge National Laboratory, Oak Ridge, TN 37831 (USA) 
Efficient production of light olefins from renewable biomass is a vital and challenging target to achieve future sustainable chemical processes. Here we report a hetero-atomic MFI-type zeolite (NbAIS-1), over which aqueous solutions of $\gamma$-valerolactone (GVL), obtained from biomass-derived carbohydrates, can be quantitatively converted to butenes with a yield of $>99 \%$ at ambient pressure under continuous flow conditions. NbAIS-1 incorporates simultaneously niobium(V) and aluminium(III) centres into the framework and thus has a desirable distribution of Lewis and Brønsted acid sites with optimal strength. Synchrotron X-ray diffraction and absorption spectroscopy show that there is cooperativity between $\mathrm{Nb}(\mathrm{V})$ and Brønsted acid sites on confined adsorption of GVL, while the catalytic mechanism for conversion of confined GVL to butenes is revealed by in situ inelastic neutron scattering, coupled with modelling. This study offers a prospect for the sustainable production of butene as a platform chemical for the manufacture of renewable materials.

Approximately 400 million tonnes of light olefins (ethene, propene and butenes) are produced each year for polymer, chemical and pharmaceutical industries ${ }^{1-6}$. State-of-the-art processes are based on stream cracking of naphtha and thus critically rely on fossil fuels, possessing significant environmental impacts ${ }^{1}$. Catalytic production of light olefins from renewable plant biomass is a highly promising target ${ }^{7}$, and many processes have been developed to bridge future gaps in the supply of commodity chemicals from biomass ${ }^{8-11}$. In particular, biomass-derived $\gamma$-valerolactone (GVL), obtained from agricultural waste via low-cost, high-yield commercial processes (production scale at 27 tonnes in 2018), has been identified as a sustainable resource to produce butenes ${ }^{12}$, which, through well-established petroleum processes, can be readily transformed to a wide spectrum of petrochemicals, such as propene ${ }^{2,13}, 1,3$-butadiene $e^{14}$, aromatics ${ }^{15}$, liquid fuels ${ }^{2,9}$, polyethylene $e^{2,16}$ and polybutene $e^{2,17}$. In this respect, development of efficient catalytic processes to convert GVL to butenes is of vital importance. This conversion involves the ring-opening and decarboxylation reactions catalysed over solid acids, and amorphous $\mathrm{SiO}_{2} / \mathrm{Al}_{2} \mathrm{O}_{3}$, ZSM-5, La/ZSM-5, Ni 2 P/MCM-41, ZnAlPO-5 and $\mathrm{Pd} / \mathrm{Nb}_{2} \mathrm{O}_{5}$ have been studied ${ }^{9,15,18-24}$. Using a $30 \mathrm{wt} \%$ GVL feedstock at $375^{\circ} \mathrm{C}$ and atmospheric pressure, a butene yield of $75 \%$ has been achieved over the $\mathrm{SiO}_{2} / \mathrm{Al}_{2} \mathrm{O}_{3}$ catalyst ${ }^{9}$. Commercial supplies of GVL from biorefineries are aqueous solutions with GVL concentrations between 20-40 wt $\%{ }^{15}$; however, the water in the reaction can partially or completely deactivate solid-acid catalysts by coordinating to the acid sites and forming acid-base adducts ${ }^{25,26}$. Thus, the design of an efficient, yet water-tolerant catalyst for this 
conversion remains a fundamental challenge. Recently, emerging niobium-based catalysts have shown to possess marked water-tolerance $\mathrm{e}^{25-32}$ and exceptional activities for the hydrodeoxygenation of biomass under mild conditions ${ }^{33-35}$.

Here, we describe the development of a hetero-atomic MFI-type zeolite (denoted as NbAlS-1) and its catalytic activity for the conversion of GVL to butenes. NbAlS-1 integrates, for the first time, both $\mathrm{Nb}(\mathrm{V})$ and $\mathrm{Al}(\mathrm{III})$ sites into the framework, and through fine-tuning of the ratio of $\mathrm{Nb}: \mathrm{Al}: \mathrm{Si}$, optimal acidity and hence reactivity of the catalyst can be achieved, promoting a quantitative production of butenes (yield >99\%) using a $30 \mathrm{wt} \% \mathrm{GVL}$ feedstock at $320^{\circ} \mathrm{C}$ and atmospheric pressure in absence of an external source of hydrogen. NbAlS-1 shows superior water-tolerance and catalytic stability over 180 hours in a continuousflow reaction. The underlying catalytic mechanism has been elucidated at a molecular level, employing a combination of in situ synchrotron X-ray powder diffraction (SXPD), X-ray absorption spectroscopy (XAS), inelastic neutron scattering (INS) and DFT calculations. These complimentary techniques revealed that the cooperativity between $\mathrm{Nb}(\mathrm{V})$ and Brønsted acid sites plays a key role in the reactivity of GVL and, compared with conventional HZSM-5, the absence of strong Brønsted acid sites in NbAlS-1 effectively hindered the formation of by-products, resulting in the observed selectivity of butenes.

Synthesis and characterisation. The hydrothermal synthesis of ZSM-5 doped with varying loadings of $\mathrm{Nb}(\mathrm{V})(0-5.58 \mathrm{wt} \%)$ and $\mathrm{Al}(\mathrm{III})(0-1.64 \mathrm{wt} \%)$ has been systematically studied, and all obtained materials exhibit the MFI-type framework (Supplementary Fig. 1), BET surface areas of 357-408 $\mathrm{m}^{2} \mathrm{~g}^{-1}$ (Supplementary Table 1), and particle size distributions between 300-500 nm (Supplementary Fig. 2, Supplementary Table 1). All zeolites studied here exhibit similar micropore volumes (Supplementary Table 1). An optimal loading of $3.81 \mathrm{wt} \% \mathrm{Nb}(\mathrm{V})$ and $1.64 \mathrm{wt} \% \mathrm{Al}(\mathrm{III})$ has been identified for the synthesis of NbAlS-1(0.027/0.04/1) (yield=95\%). The atomic ratio of $\mathrm{Nb} / \mathrm{Al} / \mathrm{Si}$ has been determined by energy dispersive X-ray (EDX) analysis to be 0.027/0.04/1 with homogeneous distributions of metal ions (Fig. 1a-e). The vibrational modes of Nb-O-Si moieties ${ }^{36}$ in NbAlS-1 $(0.027 / 0.04 / 1)$ have been observed by FTIR $\left(971 \mathrm{~cm}^{-1}\right.$; Fig. 1f) and Raman spectroscopy (921 and $973 \mathrm{~cm}^{-1}$; Fig. 1g), indicating the incorporation of $\mathrm{Nb}(\mathrm{V})$ centres as the framework T-sites.

The successful incorporation of $\mathrm{Nb}(\mathrm{V})$ and $\mathrm{Al}(\mathrm{III})$ into framework sites is further confirmed by electron paramagnetic resonance (EPR) spectroscopy. Although NbS-1 (the isostructural analogue with 0\% 
Al loading) and NbAlS-1 are EPR silent due to the diamagnetic $\mathrm{Nb}(\mathrm{V})$ and $\mathrm{Al}(\mathrm{III})$ ions, characteristic paramagnetic centres can be induced by $\gamma$-irradiation of the zeolites ${ }^{36}$. EPR spectra of $\gamma$-irradiated NbS$1(0.027 / 1)$ and NbAlS-1(0.027/0.04/1) show a wide, structured signal that spreads over a magnetic field range of ca. $350 \mathrm{mT}$ (Fig. 1h) with a 10-line hyperfine structure, consistent with coupling of an unpaired electron to a ${ }^{93} \mathrm{Nb}$ nucleus $(I=9 / 2 ; 100 \%$ natural abundance). The site has axial symmetry with $g$-values of $g_{\|}=1.866, g_{\perp}=1.935$ and hyperfine couplings of $A^{\mathrm{Nb}} \|=0.0289, A^{\mathrm{Nb}}{ }_{\perp}=0.0148 \mathrm{~cm}^{-1}$ (Supplementary Table 2), consistent with the previous characterisation of $\mathrm{Nb}$ (IV) centres generated at the pseudo-tetrahedral $\mathrm{NbO}_{4}$ units in the framework of silicalite- $1^{36}$, whereas this signal is not observed in $\gamma$-irradiated HZSM-5 or $\mathrm{Nb}_{2} \mathrm{O}_{5-}$ HZSM-5 mixtures (Fig. 1h), indicative that the $\mathrm{Nb}(\mathrm{V})$ ion in NbAlS-1 is solely incorporated into framework sites, rather than deposited as $\mathrm{Nb}_{2} \mathrm{O}_{5}$ phases. A second narrow signal with hyperfine structure observed in the spectra of $\gamma$-irradiated HZSM-5 and NbAlS-1 (Fig. 1i, Supplementary Table 2), arises from an electron hole defect on a framework oxygen atom in an $\mathrm{Al}-\mathrm{O}^{-}-\mathrm{Si}_{\text {site }}{ }^{37}$, where the structure arises from hyperfine coupling with the ${ }^{27} \mathrm{Al}$ nucleus ( $\mathrm{I}=5 / 2 ; 100 \%$ natural abundance). In $\gamma$-irradiated $\mathrm{NbS}-1$, a sharp signal is observed, but the hyperfine structure is lost, consistent with the absence of Al(III). Thus EPR measurements provide convincing evidence for the incorporation of both $\mathrm{Nb}(\mathrm{V})$ and $\mathrm{Al}(\mathrm{III})$ into framework sites in NbAlS-1, enabling the fine-tuning of its framework acidity and hence catalytic activity.

Pyridine-adsorption FTIR (Py-IR) spectroscopy has been used to characterise the nature of acidity in these zeolites (Supplementary Fig. 3 and Supplementary Table 3). NbS-1 exhibits solely Lewis acidity due to the presence of $\mathrm{Nb}(\mathrm{V})$, whereas NbAlS-1 shows both Lewis and Brønsted acidity, which arises from the dual functionality of $\mathrm{Nb}(\mathrm{V})$ and $\mathrm{Al}(\mathrm{III})$ sites. Notably, the nature of the acidity in NbAlS-1 is distinct to that of HZSM-5: the ratio of Lewis/Brønsted acid sites in NbAlS-1 is 4.69, twelve times that of HZMS-5. The acidity has been quantified by ammonia temperature-programmed desorption $\left(\mathrm{NH}_{3}-\mathrm{TPD}\right)$ (Supplementary Fig. 4 and Supplementary Table 3). HZSM-5 displays both strong and weak acid sites with a total amount of 0.4-0.63 mmol g $\mathrm{g}^{-1}$ and NbS-1 exhibits minor weak acid sites of $0.04 \mathrm{mmol} \mathrm{g}^{-1}$. Interestingly, NbAlS-1 shows only weak acid sites, but their concentration is considerably higher $\left(0.22 \mathrm{mmol} \mathrm{g}^{-1}\right)$ than that of $\mathrm{NbS}-1$. Thus, doping of pentavalent niobium sites into the zeolite can effectively tune the nature and distribution of framework acidity and provides an excellent platform to examine the resultant catalytic activities. 
Catalytic tests. Conversions of pure GVL have been firstly performed over a fixed-bed packed with the catalysts under flow conditions at $320^{\circ} \mathrm{C}\left(\mathrm{WHSV}=0.18 \mathrm{~h}^{-1}\right.$; Table 1$) . \mathrm{HZSM}-5$ with varying Al/Si ratios show GVL conversions of $75-92 \%$ and moderate butene yields of $33.1-44.1 \%$ (Entries $1-3$ ). This is due to the formation of considerable amounts of 2-cyclopentenone, aromatics, polycyclic aromatics as by-products and coke over strong acid sites (Supplementary Figs. 5 and 6). On the other hand, the lack of Brønsted acid sites in NbS-1 gives very low butene yields ( 7\%) and GVL conversions (32\%) (Entries 4 and 5). In contrast, a $96 \%$ GVL conversion with $80.4 \%$ butene yield has been achieved over NbAlS-1(0.027/0.04/1) (Entry 6). This suggests that the strength and nature of the framework acidity are key parameters for optimising its performance. By introducing $\mathrm{Nb}(\mathrm{V})$ as weak Lewis acid sites to weaken the strong $\mathrm{Al}(\mathrm{III})$ acid sites in NbAlS-1, the formation of by-products was effectively inhibited, leading to high selectivities to butenes over NbAlS-1.

The catalytic performance of these zeolites has been further tested using $30 \mathrm{wt} \%$ and $60 \mathrm{wt} \%$ aqueous solution of GVL (Table 1 and Supplementary Table 4); the former is of direct relevance to practical processes ${ }^{15}$. The butene yields from aqueous solutions of GVL over HZSM-5 with varying Si/Al ratio decreased to 22.2-29.2\% owing to the deactivation of acid sites in the presence of water (Entries 1-3, 11 and 13-15). Significantly, quantitative production of butenes (yield >99\%) has been achieved over NbAlS$1(0.027 / 0.04 / 1)$ using a 30wt\% GVL feedstock (Entry 16), demonstrating the significantly improved water tolerance by $\mathrm{Nb}(\mathrm{V})$ doping. Other widely-studied $\mathrm{Nb}$-containing catalysts, such as $\mathrm{Nb}_{2} \mathrm{O}_{5}$, niobic acid $\left(\mathrm{Nb}_{2} \mathrm{O}_{5} \cdot \mathrm{H}_{2} \mathrm{O}\right)$ and $\mathrm{NbOPO}_{4}$, have also been tested for this reaction and, as expected, these catalysts all exhibit excellent water tolerance (Entries 8-10 and 17-19). A butene yield of 78.3\% has been obtained from the conversion of $30 \mathrm{wt} \%$ aqueous solutions of $\mathrm{GVL}$ over $\mathrm{NbOPO}_{4}$, which however has a much lower utilisation efficiency of $\mathrm{Nb}$ compared with $\mathrm{NbAlS}-1(0.027 / 0.04 / 1)(46 \%$ and $3.8 \%$, respectively, in terms of $\mathrm{Nb}$ concentration). The performance of NbAlS-1(0.027/0.04/1) compares favourably with all state-of-the-art catalysts (Supplementary Table 5). As previously observed in niobic acids systems, water can only partially coordinate to $\mathrm{Nb}(\mathrm{V})$ centres, leaving sufficient positive charges on $\mathrm{NbO}_{4}$ moieties to bind substrates ${ }^{26,31}$. Indeed, the formation of coke, 2-cyclopentenone and other by-products is effectively inhibited over NbAlS$1(0.027 / 0.04 / 1)$ by the presence of water (Supplementary Fig. 7 and Table 1). The excellent stability of NbAlS-1(0.027/0.04/1) has been demonstrated by both cycling and time-on-stream tests, where the yield of butenes remained at $>99 \%$ after 180 hours of reaction (Fig. 2a-b). The used catalyst has been characterised 
by $\mathrm{N}_{2}$-sorption, synchrotron XPD, EDX, FTIR, EPR (upon ${ }^{60} \mathrm{Co} \gamma$-irradiation), XAS, ${ }^{27} \mathrm{Al}$ NMR, $\mathrm{NH}_{3}$-TPD and pyridine-IR (Fig. 2c-d, Supplementary Figs. 8-12). Importantly, all these results confirm that there is little change on the structure and acidic sites of used NbAlS-1, demonstrating the excellent structural stability of the bifunctional zeolite. Interestingly, little change was observed on the structure and acidic sites of used HZSM-5(0.04/1) (Fig. 2c-d, Supplementary Figs. 11-13), indicating that the decrease of catalytic activity of HZSM-5 upon exposure to water compared with reactions using pure GVL (Table 1, entries 2, 11 and 14) is primarily due to partial poisoning of acidic sites, consistent with the literature reports ${ }^{25,26}$.

Studies of the coordination environment of $\mathbf{N b}(\mathrm{V})$ sites. To understand the effect of active $\mathrm{Nb}(\mathrm{V})$ sites, their local environment was interrogated through $\mathrm{Nb}$ K-edge XAS. The absorption edge positions for both NbAlS-1(0.027/0.04/1) and NbS-1(0.027/1) from X-ray absorption near edge spectra (XANES) are consistent with the pentavalent oxidation state ${ }^{38}$ with the as-prepared samples exhibiting a common weak pre-edge peak (Fig. 3a). The weak nature of this pre-edge feature can be attributed to disruption of the pseudo-tetrahedral $\mathrm{Nb}$ environment via water coordination (Fig. 3b) ${ }^{38}$. On adsorption of GVL to the pores of $\mathrm{NbAlS}-1$, the pre-edge position is further influenced with an apparent blue-shift $(\sim 0.8 \mathrm{eV})$; in contrast, no shift is witnessed for NbS-1. This reflects both greater electron donation from $\mathrm{GVL}^{39}$, but also the preferred adsorption geometry within the bifunctional zeolite NbAlS-1, which facilitates closer interaction between the $\mathrm{Nb}(\mathrm{V})$ sites and the substrate. This conclusion is verified through extended $\mathrm{X}$-ray absorption fine structure (EXAFS) analysis (Fig. 3c). Fitting of the first coordination shell reveals an increase in the average $\mathrm{Nb}=\mathrm{O}$ bond length due to the presence of an adsorbate and subsequent decrease in double bond nature, whilst the siloxane bridges remain unaffected (Supplementary Table 6). The effect is apparent in both NbAlS-1 and NbS-1 systems, and the NbAlS-1 system is perturbed to a significantly greater extent, 0.22 vs $0.06 \AA$ increase in bond length, respectively. Furthermore, fitting of the second coordination shell discredits the potential for bulk $\mathrm{Nb}_{2} \mathrm{O}_{5}$ formation, which confirms the location of $\mathrm{Nb}(\mathrm{V})$ to be solely within the framework, consisting with the EPR observation. Thus, the framework $\mathrm{Nb}(\mathrm{V})$ site plays a key role in the adsorption of GVL in NbAlS-1.

Determination of adsorption domains for GVL. The binding domains of GVL within these zeolites have been determined from in situ SXPD data (Supplementary Fig. 14 and Supplementary Note 
Interaction between GVL and $\mathrm{Nb} / \mathrm{Al} / \mathrm{H}$ sites). All datasets enabled direct observation of two independent binding sites for GVL (I and II) within the pores (typical $\mathrm{R}_{\mathrm{wp}}=4-6 \%$; Fig. 4, Supplementary Fig. 15, Supplementary Tables 7-12) without notable structural phase change of the framework (Supplementary Fig. 14). GVL ${ }^{\mathrm{I}}$ and $\mathrm{GVL}^{\mathrm{II}}$ are located near the intersection of straight and sinusoidal channels, respectively (Fig. 4a-c). Importantly, adsorbed GVL molecules show three distinct spatial orientations within the framework of HZSM-5, NbS-1 and NbAlS-1, indicating the presence of varying host-guest interactions. In the straight channel of HZSM-5, GVL ${ }^{\mathrm{I}}$ interacts with a bridging $\mathrm{O}(\mathrm{H})$-centre through its $\mathrm{C}=\mathrm{O}$ group $[\mathrm{C}=\underline{\mathrm{O}} \cdots \underline{\mathrm{O}}=$ 3.812(54) $\AA$ ] via a weak hydrogen bond (Fig. 4d). In NbS-1, GVL directly binds to framework T-sites $\left(\mathrm{NbO}_{4}\right.$ moieties) via its intra-ring O-centre $\left[\mathrm{T}^{\cdots} \underline{\mathrm{OC}}_{4}=4.005(39) \AA ̊ ․\right.$ in NbAlS-1 forms host-guest interactions with both bridging $\mathrm{O}(\mathrm{H})$-centres and T sites $[\mathrm{C}=\underline{\mathrm{O}} \cdots \underline{\mathrm{O}}=3.574(141)$ $\left.\AA ; \mathrm{Nb}^{\cdots} \underline{\mathrm{OC}}_{4}=3.789(75) \AA ̊\right]$ (Fig. 4f). Similar but more notable observations are observed for GVL ${ }^{\mathrm{II}}$ (Fig. 4gi). For example, $\mathrm{GVL}^{\mathrm{II}}$ forms a weak hydrogen bond interaction to a bridging $\mathrm{O}(\mathrm{H})$-centre $[\mathrm{C}=\underline{\mathrm{O}} \cdots \underline{\mathrm{O}}=$ 3.210(38) $\mathrm{A}]$ in HZMS-5 and a dipole interaction to the framework T-site $\left[\mathrm{Nb} \cdots \underline{\mathrm{OC}}_{4}=3.560(40) \AA\right]$ in NbS1, whereas in NbAlS-1, it displays a combination of these two types of interactions $[\mathrm{C}=\underline{\mathrm{O}} \cdots \underline{\mathrm{O}}=3.055(57) \AA$; $\left.\mathrm{Nb} \cdots \underline{\mathrm{OC}}_{4}=3.490(75) \AA\right]$. These results strongly indicate that Brønsted or Lewis acid sites alone in HZMS-5 or NbS-1 can only serve as "mono-dentate" binding sites for GVL molecules, whereas the cooperativity between these two types of acid sites results in the optimal adsorption of GVL via a "chelating" mechanism in NbAlS-1. Recently, the distribution of $\mathrm{SiO}(\mathrm{H}) \mathrm{Al}$ sites in LTA zeolite has been studied using periodic DFT calculations and $\mathrm{INS}^{40,41}$. Here, ${ }^{29} \mathrm{Si} \mathrm{NMR}$, INS and DFT calculations demonstrate the presence of $\mathrm{NbO}(\mathrm{SiO})_{\mathrm{n}} \mathrm{Al}(\mathrm{n}=1$ or 2$)$ species in NbAlS-1, which promotes the preferred adsorption of GVL in NbAlS-1 (Supplementary Figs. 16-18, Supplementary Tables 13-15, and Supplementary Note Distribution of Nb/A1/H sites). Thus, the excellent catalytic activity of NbAlS-1 for butene production is originated from (i) the highly confined adsorption of GVL in the framework pores; (ii) greatly reduced Brønsted acidity of the resultant framework ( $70 \%$ comparing to HZSM-5), leading to the rapid desorption of butene products from the catalyst surface, thus preventing their further reactions to form various cyclic by-products and cokes.

Studies of reaction mechanism. Combined INS and DFT calculations have been applied to investigate the vibrational dynamics of GVL@NbAlS-1(0.027/0.04/1) in operando. Recently, this technique has been employed to investigate the vibrational dynamics of $\mathrm{C}_{3} \mathrm{H}_{6} @ \mathrm{ZSM}-5 .{ }^{42}$ The INS spectra of solid and 
adsorbed GVL were recorded and modelled via DFT calculations (Supplementary Figs. 19-23, Fig 5a-b, Supplementary Table 16 and Supplementary Note inelastic neutron scattering), allowing a full assignment of the spectral features for GVL. Comparison of INS spectra of adsorbed GVL (spectrum of empty cell has been subtracted) and solid GVL shows a number of observations (Fig. 5a). There is little change in the lowenergy modes $\left(<100 \mathrm{~cm}^{-1}\right)$ of GVL on adsorption, indicating adsorbed GVL molecules are highly ordered and confined within the framework. The peaks at $1060 \mathrm{~cm}^{-1}$ (assigned to C4-O1 stretching) and at $1127 \mathrm{~cm}^{-1}$ (assigned to C1-O1-C4 asymmetric stretching) decrease significantly in intensity and shift to $1046 \mathrm{~cm}^{-1}$ and $1121 \mathrm{~cm}^{-1}$, respectively, indicating that $\mathrm{C} 4-\mathrm{O} 1$ and $\mathrm{C} 1-\mathrm{O} 1$ bonds are activated on adsorption via $\mathrm{O} 1$ to the $\mathrm{Nb}(\mathrm{V})$ site. Meanwhile, the peaks at $151 \mathrm{~cm}^{-1}$ (assigned to $\mathrm{C} 4$ out-of-plane wagging) and at $827 \mathrm{~cm}^{-1}$ (assigned to ring distortion) also decrease in intensity owing to the hindered motion of $\mathrm{O} 1$ on adsorption. The modes of C4-C5 torsion $\left(273 \mathrm{~cm}^{-1}\right)$ and rocking $\left(317 \mathrm{~cm}^{-1}\right)$ are also affected by adsorption via the O1 centre, and shift to lower energy at 234 and $308 \mathrm{~cm}^{-1}$, respectively. The marked red-shift of $\Delta=39 \mathrm{~cm}^{-1}$ for the torsion mode confirms the restricted motion of the methyl group on adsorption $\left[-\mathrm{CH}_{3} \cdots \mathrm{O}_{\text {zeolite }}=2.032(65) \AA\right.$ ] The rocking mode of $\mathrm{C} 1=\mathrm{O} 2\left(512 \mathrm{~cm}^{-1}\right)$ has disappeared completely, consistent with the formation of hydrogen bonds to the Brønsted acid site. The peak at $181 \mathrm{~cm}^{-1}$ (assigned to the twisting mode of O2=C1-C2) shifts to $173 \mathrm{~cm}^{-1}$, further confirming the adsorption of GVL via the $\mathrm{O} 2$ centre on the Brønsted acid sites. These findings are highly consistent with the X-ray crystal structures.

Adsorbed GVL molecules on NbAlS-1(0.027/0.04/1) underwent a first catalytic conversion at $280{ }^{\circ} \mathrm{C}$ for 3 minutes (Fig. 5a). The peaks at 1046, 1121 and $827 \mathrm{~cm}^{-1}$ (all involving C4-O1 vibrational modes) further reduce in intensity, indicating that the $\mathrm{C} 4-\mathrm{O} 1$ bond has been selectively activated. To promote further conversion, a second reaction was carried out at $300{ }^{\circ} \mathrm{C}$ for 3 minutes (Fig. 5a). All INS features related to C4-O1 modes (1046 and $\left.1121 \mathrm{~cm}^{-1}\right)$ and ring deformation $\left(609,655,802,827\right.$ and $\left.899 \mathrm{~cm}^{-1}\right)$ have disappeared, suggesting the ring-opening reaction via selective cleavage of the C4-O1 bond in activated GVL. Meanwhile, $\mathrm{O} 2$ is protonated, leading to the decrease of peak intensities at 530 and $173 \mathrm{~cm}^{-1}$ (assigned to $\mathrm{C} 1$ and $\mathrm{C} 2$ out-of-plane wagging modes, respectively). A final reaction was conducted at $320{ }^{\circ} \mathrm{C}$, and these two peaks (530 and $173 \mathrm{~cm}^{-1}$ ) disappeared, consistent with the decarboxylation reaction via cleavage of the C1-C2 bond (Fig. 5a). Meanwhile, new features appeared at 212, 229, 254, 366, 407 and $437 \mathrm{~cm}^{-1}$, fully consistent with the formation of butenes (Supplementary Fig. 24). 
A full catalytic circle has been constructed based upon the structural, dynamic and modelling results (Fig. 5c). Over NbAlS-1, the adsorption of GVL occurs on $\mathrm{Nb}(\mathrm{V})$ and Brønsted acid sites in a "chelating mode" via $\mathrm{O} 1$ and $\mathrm{O} 2$ centres, followed by a ring-opening reaction of activated GVL via selective cleavage of the $\mathrm{C} 4-\mathrm{O} 1$ bond at elevated temperatures. Meanwhile, $\mathrm{C} 1=\mathrm{O} 2$ is protonated via proton transfer from the Brønsted acid sites. On addition of the $\mathrm{H}$-shift in $\mathrm{C}_{5}$-skeleton, a $\beta$-scission occurs and $\mathrm{C} 1-\mathrm{C} 2$ bond is cleaved, yielding butenes and an equimolar $\mathrm{CO}_{2}$. By contrast, on HZSM-5, both the ring-opening and decarboxylation reactions proceed on the Brønsted acid sites (Fig. 5d). The inability for the intermediate carbocation to desorb from the strong acid sites of HZSM-5 results in its transformation to undesirable by-products of 2cyclopentenone, aromatics and coke via dehydration, aromatisation and coking, respectively.

\section{Outlook}

Powerful drivers exist for the development of efficient catalysts to enable the sustainable production of light olefins from biomass to remit our reliance on fossil fuels. NbAlS-1, integrating both $\mathrm{Nb}(\mathrm{V})$ and $\mathrm{Al}(\mathrm{III})$ sites into the MFI-zeolite framework, demonstrates an excellent catalytic performance to transform biomass-derived GVL in aqueous solutions to butenes with a quantitative yield. $\mathrm{Nb}(\mathrm{V})$ sites in the MFI framework play three vital roles: i) optimising acidity of zeolite to hinder the production of by-products; ii) cooperating with Brønsted acid sites for confined adsorption of GVL and thus activating C-O bonds; iii) resisting to water poisoning and thus enhancing the overall catalytic stability. Upon reaction completion, the liquid phase product contains only water and gas phase product is an equimolar mixture of butenes and $\mathrm{CO}_{2}$, which can be facilely separated based upon the difference in their boiling points $\left(\Delta=72^{\circ} \mathrm{C}\right)$. While butenes are used as a platform chemical, recovered $\mathrm{CO}_{2}$ can be readily sequestrated. The industrial-scale synthesis of NbAlS-1 could be achieved based upon the infrastructure widely used for the synthesis of ZSM-5, which coupled with its high stability, further demonstrates its potential for practical applications.

\section{References:}

1. Torres Galvis, H. M. \& de Jong, K. P. Catalysts for production of lower olefins from synthesis gas: a review. ACS Catal. 3, 2130-2149 (2013).

2. Bender, M. An overview of industrial processes for the production of olefins $-\mathrm{C}_{4}$ hydrocarbons. ChemBioEng Rev. 1, 136-147 (2014).

3. Galvis, H. M. T. et al. Supported iron nanoparticles as catalysts for sustainable production of lower olefins. Science 335, 835-838 (2012). 
4. Amghizar, I., Vandewalle, L. A., Van Geem, K. M. \& Marin, G. B. New trends in olefin production. Engineering 3, 171-178 (2017).

5. Jiao, F. et al. Selective conversion of syngas to light olefins. Science 351, 1065-1068 (2016).

6. Zacharopoulou, V. \& Lemonidou, A. A. Olefins from biomass intermediates: a review. Catalysts 8, 2 (2018).

7. Tuck, C. O., Pérez, E., Horváth, I. T., Sheldon, R. A. \& Poliakoff, M. Valorization of biomass: deriving more value from waste. Science 337, 695-699 (2012).

8. Bozell, J. J. Connecting biomass and petroleum processing with a chemical bridge. Science 329, $522-523$ (2010).

9. Bond, J. Q., Alonso, D. M., Wang, D., West, R. M. \& Dumesic, J. A. Integrated catalytic conversion of $\gamma$ valerolactone to liquid alkenes for transportation fuels. Science 327, 1110-1114 (2010).

10.Jing, Y., Guo, Y., Xia, Q., Liu, X. \& Wang, Y. Catalytic production of value-added chemicals and liquid fuels from lignocellulosic biomass. Chem 5, 2520-2546 (2019).

11.Corma, A., Iborra, S. \& Velty, A. Chemical routes for the transformation of biomass into chemicals. Chem. Rev. 107, 2411-2502 (2007).

12. Yan, K., Yang, Y., Chai, J. \& Lu, Y. Catalytic reactions of gamma-valerolactone: a platform to fuels and valueadded chemicals. Appl. Catal. B Environ. 179, 292-304 (2015).

13.Lin, L. et al. Acid strength controlled reaction pathways for the catalytic cracking of 1-butene to propene over ZSM5. J. Catal. 309, 136-145 (2014).

14.Hong, E., Park, J.-H. \& Shin, C.-H. Oxidative dehydrogenation of n-butenes to 1,3-butadiene over bismuth molybdate and ferrite catalysts: a review. Catal. Surv. Asia 20, 23-33 (2016).

15. Ye, L. et al. Decarboxylation of lactones over Zn/ZSM-5: elucidation of the structure of the active site and molecular interactions. Angew. Chem. Int. Ed. 56, 10711-10716 (2017).

16.Shao, H., Lv, Z., Sun, Z., Liu, C. \& He, A. Synthesis of spherical polyethylene/poly(1-butene) reactor blends with two-stage sequence polymerization technology. Polymer 144, 72-79 (2018).

17.Kim, M. S., Park, M. S., Seo, H. J. \& Lee, S. H. Method for preparing polybutene, US 9683060B2 (2017).

18. Kellicutt, A. B., Salary, R., Abdelrahman, O. A. \& Bond, J. Q. An examination of the intrinsic activity and stability of various solid acids during the catalytic decarboxylation of $\gamma$-valerolactone. Catal. Sci. Technol. 4, 2267-2279 (2014).

19.Bond, J. Q., Wang, D., Alonso, D. M. \& Dumesic, J. A. Interconversion between $\gamma$-valerolactone and pentenoic acid combined with decarboxylation to form butene over silica/alumina. J. Catal. 281, 290-299 (2011).

20.Bond, J. Q., Martin Alonso, D., West, R. M. \& Dumesic, J. A. $\gamma$-Valerolactone ring-opening and decarboxylation over $\mathrm{SiO}_{2} / \mathrm{Al}_{2} \mathrm{O}_{3}$ in the presence of water. Langmuir 26, 16291-16298 (2010).

21.Bond, J. Q., Jungong, C. S. \& Chatzidimitriou, A. Microkinetic analysis of ring opening and decarboxylation of $\gamma$ valerolactone over silica alumina. J. Catal. 344, 640-656 (2016).

22. Yun, G.-N., Ahn, S.-J., Takagaki, A., Kikuchi, R. \& Oyama, S. T. Hydrodeoxygenation of $\gamma$-valerolactone on bimetallic NiMo phosphide catalysts. J. Catal. 353, 141-151 (2017).

23.Lin, W.-C. et al. Zinc-incorporated microporous molecular sieve for mild catalytic hydrolysis of $\gamma$-valerolactone: a new selective route for biomass conversion. ChemSusChem 11, 4214-4218 (2018).

24.Serrano-Ruiz, J. C., Braden, D. J., West, R. M. \& Dumesic, J. A. Conversion of cellulose to hydrocarbon fuels by progressive removal of oxygen. Appl. Catal. B Environ. 100, 184-189 (2010).

25.Okuhara, T. Water-tolerant solid acid catalysts. Chem. Rev. 102, 3641-3666 (2002).

26. Nakajima, K. et al. $\mathrm{Nb}_{2} \mathrm{O}_{5} \cdot \mathrm{nH}_{2} \mathrm{O}$ as a heterogeneous catalyst with water-tolerant Lewis acid sites. J. Am. Chem. Soc. 133, 4224-4227 (2011). 
27.Zhang, Y. et al. Direct conversion of biomass-derived carbohydrates to 5-hydroxymethylfurural over water-tolerant niobium-based catalysts. Fuel 139, 301-307 (2015).

28.Zhang, Y. et al. Mesoporous niobium phosphate : an excellent solid acid for the dehydration of fructose to 5hydroxymethylfurfural in water. Catal. Sci. Technol. 2, 2485-2491 (2012).

29. Takagaki, A., Tagusagawa, C. \& Domen, K. Glucose production from saccharides using layered transition metal oxide and exfoliated nanosheets as a water-tolerant solid acid catalyst. Chem. Commun. 5363-5365 (2008).

30.Carniti, P., Gervasini, A., Biella, S. \& Auroux, A. Niobic acid and niobium phosphate as highly acidic viable catalysts in aqueous medium: fructose dehydration reaction. Catal. Today 118, 373-378 (2006).

31.Carniti, P., Gervasini, A., Bossola, F. \& Dal Santo, V. Cooperative action of Brønsted and Lewis acid sites of niobium phosphate catalysts for cellobiose conversion in water. Appl. Catal. B Environ. 193, 93-102 (2016).

32. Nowak, I. \& Ziolek, M. Niobium compounds: preparation, characterization, and application in heterogeneous catalysis. Chem. Rev. 99, 3603-3624 (1999).

33. Serrano-Ruiz, J. C., Wang, D. \& Dumesic, J. A. Catalytic upgrading of levulinic acid to 5-nonanone. Green Chem. 12, 574 (2010).

34.Xia, Q. et al. Direct hydrodeoxygenation of raw woody biomass into liquid alkanes. Nat. Commun. 7, 11162 (2016).

35. Shao, Y. et al. Selective production of arenes via direct lignin upgrading over a niobium-based catalyst. Nat. Commun. 8, 16104 (2017).

36.Prakash, A. M. \& Kevan, L. Synthesis of niobium silicate molecular sieves of the MFI structure: evidence for framework incorporation of the niobium ion. J. Am. Chem. Soc. 120, 13148-13155 (1998).

37. Wichterlová, B., Nováková, J. \& Prášil, Z. Structure of defects in $\gamma$-irradiated ZSM-5 and Y zeolites: an ESR study. Zeolites 8, 117-121 (1988).

38.Corma, A., Llabrés i Xamena, F. X., Prestipino, C., Renz, M. \& Valencia, S. Water Resistant, Catalytically active $\mathrm{Nb}$ and Ta isolated Lewis acid sites, homogeneously distributed by direct synthesis in a beta zeolite. J. Phys. Chem. C 113, 11306-11315 (2009).

39.Duereh, A., Sato, Y., Smith, R. L. \& Inomata, H. Analysis of the cybotactic region of two renewable lactone-water mixed-solvent systems that exhibit synergistic Kamlet-Taft basicity. J. Phys. Chem. B 120, 4467-4481 (2016).

40.Lemishko, T., Valencia, S., Rey, F., Jiménez-Ruiz, M. \& Sastre, G. Inelastic neutron scattering study on the location of Brønsted acid sites in high silica LTA zeolite. J. Phys. Chem. C 120, 24904-24909 (2016).

41.Lemishko, T. et al. Inelastic neutron scattering study of the aluminum and Brønsted site location in aluminosilicate LTA zeolites. J. Phys. Chem. C 122, 11450-11454 (2018).

42. Hawkins, A. P. et al. Investigation of the dynamics of 1-Octene adsorption at $293 \mathrm{~K}$ in a ZSM-5 catalyst by inelastic and quasielastic neutron scattering. J. Phys. Chem. C 123, 417-425 (2019).

Acknowledgements: We thank EPSRC (EP/P011632/1) and the University of Manchester for funding. We thank EPSRC for funding and the EPSRC National Service for EPR Spectroscopy at Manchester. AMS thanks the Russian Science Foundation (Grant no. 17-73-10320) and Royal Society of Chemistry for funding. We are grateful to Oak Ridge National Laboratory (ORNL), the ISIS Facility and Diamond Light Source (DLS) for access to the beamlines VISION, TOSCA and I11, respectively. We acknowledge DLS for the provision of beamtime at B18 (UK Catalysis Hub SP15151, Rapid access SP24726) and Dr. G. Cibin and Dr. V. Celorrio for help at B18 beamline. We acknowledge the support of The University of Manchester's Dalton Cumbrian Facility (DCF), a partner in the National Nuclear User 
Facility, the EPSRC UK National Ion Beam Centre and the Henry Royce Institute. We recognise Dr. R. Edge and Dr. K. Warren for their assistance during the ${ }^{60} \mathrm{Co} \gamma$-irradiation processes. We thank Prof. Andreas Jentys from the Technical University of Munich and ISIS Facility for the measurement of the INS spectrum of iso-butene as part of RB20053 experimental proposal. We thank C. Webb for help with GC-MS; D. Moulding for help with Raman spectroscopy; M. Kibble for help at TOSCA beamline. The computing resources were made available through the VirtuES and the ICE-MAN projects, funded by Laboratory Directed Research and Development program and Compute and Data Environment for Science (CADES) at ORNL.

Author contributions: L.L. and M.F carried out syntheses and characterisation of the zeolite samples. L.L. and X.H. carried out catalytic tests. L.L., A.M.S, F.T. and E.J.L.M collected and analysed EPR data. L.L. and C.M.A.P. collected and analysed the XAS data. L.L., J.C., I.D.S. and C.C.T. collected and analysed the synchrotron X-ray diffraction data. Z.T and Y.L. collected and analysed the py-IR data. L.L., Y.C, L.L.D., S.R. and A.J.R. collected and analysed the neutron scattering data and carried out DFT modelling. S.Y. was responsible for the overall direction of the project and preparation of the manuscript, with contributions from all authors.

\section{Methods}

Catalyst preparation. HZSM-5 samples were purchased from Alfa Aesar and denoted as HZSM-5(Al/Si mole ratio). NbAlS-1 and NbS-1 samples were prepared by hydrothermal synthesis, and denoted as NbAlS-1(Nb/Al/Si mole ratio) and $\mathrm{NbS}-1(\mathrm{Nb} / \mathrm{Si}$ mole ratio), respectively. In a typical synthesis, aluminium isopropoxide (99.99+\%, Sigma Aldrich) was first dissolved in deionised water, into which tetrapropylammonium hydroxide solution (TPAOH, $1.0 \mathrm{M}$ in $\mathrm{H}_{2} \mathrm{O}$, Sigma Aldrich) as the structure-directing agent was added. After the mixture was stirred at room temperature for $2 \mathrm{~h}$, niobium ethoxide (99.95\%, Sigma Aldrich) was added and the mixture was stirred for another $2 \mathrm{~h}$. Then tetraethyl orthosilicate (98\%, Sigma Aldrich) was added dropwise and the mixture was stirred for another $2 \mathrm{~h}$, resulting in a gel with a chemical composition of $1 \mathrm{Si}: \mathrm{xAl}: \mathrm{yNb}: 0.25 \mathrm{TPAOH}: 15 \mathrm{H}_{2} \mathrm{O}$ (x and y were determined by the target $\mathrm{Al} / \mathrm{Si}$ and $\mathrm{Nb} / \mathrm{Si}$ mole ratios, respectively). The gel was transferred into a 46-mL Teflon-lined stainless steel autoclave, which was sealed and heated at $170{ }^{\circ} \mathrm{C}$ for $48 \mathrm{~h}$. The solid products were centrifuged, washed with deionised water, dried overnight at $80^{\circ} \mathrm{C}$, and finally calcined at $550^{\circ} \mathrm{C}$ under air flow for $6 \mathrm{~h}$. NbS-1 samples were synthesised by the same procedure but without the addition of aluminium isopropoxide. Except the yield (30\%) of NbAlS-1(0.04/0.027/1), the typical yields of all zeolites in this study are $90-95 \%$. $\mathrm{NbOPO}_{4}$ was synthesised by a hydrothermal method at $\mathrm{pH}=2$ according to literature ${ }^{43}$. Nb-oxide $\left(\mathrm{Nb}_{2} \mathrm{O}_{5}\right)$ and niobic-acid $\left(\mathrm{Nb}_{2} \mathrm{O}_{5} \cdot \mathrm{nH}_{2} \mathrm{O}\right)$ samples were purchased from Sigma Aldrich and CBMM, Brazil, respectively. The methods of zeolite characterisation were described in detail in Supplementary Methods Catalyst characterisation.

Catalytic testing. Catalytic reactions were carried out in a stainless steel continuous-flow reactor $(12.7 \mathrm{~mm}$ i.d.). Two grams of catalyst was pressed, crushed, and sorted into grains by 40-60 meshes, which were then activated at $450{ }^{\circ} \mathrm{C}$ for $3 \mathrm{~h}$ under a nitrogen flow before the reaction. GVL was injected into nitrogen flow $\left(50 \mathrm{~mL} \mathrm{~min}^{-1}\right)$ by syringe pump (Cole-Parmer) and passed through the reactor at the target temperature. The output liquid products were collected and analysed by Agilent 7890B gas chromatography equipped with a HP-5 column $(30 \mathrm{~m} \times 0.32 \mathrm{~mm} \times 0.25 \mu \mathrm{m})$ and Agilent 6890N-Agilent 5973N gas chromatography-mass spectrometry (GC-MS) equipped with HP-5MS column (30 $\mathrm{m} \times 0.25 \mathrm{~mm} \times 0.25 \mu \mathrm{m})$. The output gas products were collected and analysed by Agilent Micro GC 490 equipped with PoraPLOT U column (length $10 \mathrm{~m}$ ) and Agilent 7890A-Agilent 5975C GC-MS equipped with HP-PLOT/Q 
column $(30 \mathrm{~m} \times 0.53 \mathrm{~mm} \times 40 \mu \mathrm{m})$. GVL conversion is calculated by equation i.e. $\mathrm{GVL}$ conversion $=\left(\mathrm{GVL}_{\mathrm{in}}-\mathrm{GVL}_{\mathrm{out}}\right)$ $/ \mathrm{GVL}_{\text {in }} \times 100 \%$, where $\mathrm{GVL}_{\text {in }}$ and $\mathrm{GVL}_{\text {out }}$ denote the moles of GVL in the feed and exit, respectively. Product selectivity is calculated in carbon basis, i.e. $S_{i}=\left(a_{i} \times n_{i}\right) /\left(\Sigma a_{i} \times n_{i}\right) \times 100 \%$, where $a_{i}$ and $n_{i}$ denote the carbon number and mole of product $\mathrm{i}$, respectively. $\mathrm{CO}_{2}$ is excluded in selectivity calculation. Product yield is calculated by Yield = Conversion $\times$ Selectivity $\times 100 \%$. Total carbon balances for the production from GVL typically closed to within $5 \%$.

X-ray absorption spectroscopy. Transmission $\mathrm{Nb}$ K-edge X-ray absorption spectra were collected on beamline B18 at Diamond Light Source, employing a water-cooled Si [ 311 1] double crystal monochromator and double toroidal Pt-coated mirror for beam focusing. Data collection spanned $200 \mathrm{eV}$ before the edge to $1000 \mathrm{eV}$ above it, step size of $0.5 \mathrm{eV}$; with reference, $\mathrm{Nb}$ foil spectra simultaneously collected to enable energy calibrations. GVL saturated samples were collected as a slurry, contained within a sealed Kapton capillary. Data processing was carried out in the Demeter open source software package, version 0.9.26, with XAS spectra processing (normalisation and background subtractions) and EXAFS fitting conducted within the Athena and Artemis programs within Demeter respectively. Reference niobium oxide standards, $\mathrm{NbO}_{2}$ and $\mathrm{Nb}_{2} \mathrm{O}_{5}$, were also collected after dilution in boron nitride.

High-resolution synchrotron X-ray powder diffraction (SXPD) and Rietveld refinement. SXPD data were collected on Beamline I11, Diamond Light Source, UK [wavelength=0.824869(10) Å] at room temperature. The zeolite powder was loaded in a $0.7 \mathrm{~mm}$ borosilicate glass capillary. High-resolution diffraction data were obtained from the samples using the multi-analyser crystal (MAC) detectors. The patterns were collected in the $2 \theta$ range $0-150^{\circ}$ with $0.001^{\circ}$ data step. Using the TOPAS software, the SXPD patterns were refined by the Rietveld methods. The ThompsonCox-Hastings pseudo-Voigt peak function ${ }^{44}$ was applied to describe the diffraction peaks. The scale factor and lattice parameters were allowed to refine for all diffraction patterns. The refined structural parameters include the fractional coordinates $(\mathrm{x}, \mathrm{y}, \mathrm{z})$ and isotropic displacement factors (Beq) for all atoms, and the site occupancy factors (SOF) for all $\mathrm{Nb}, \mathrm{Al}, \mathrm{Si}$ species and GVL molecules. The quality of the Rietveld refinements has been assured with low goodness-offit (gof) factors, low weighted profile factors (Rwp) and well-fitted patterns with reasonable isotropic displacement factors (Beq) within experimental errors.

Inelastic neutron scattering. INS spectra were recorded on the VISION spectrometer at Spallation Neutron Source, Oak Ridge National Laboratory (USA), as well as the TOSCA spectrometer at the ISIS Facility at the STFC Rutherford Appleton Laboratory (UK). Both VISION and TOSCA are indirect geometry crystal analyser instruments that provide a wide dynamic range with high resolution. All the INS spectra were collected after the sample was cooled and stabilised at temperatures below $15 \mathrm{~K}$.

The adsorption/reaction experiments were conducted at beamlines TOSCA and VISION and results obtained from both spectrometers are consistent. In a typical experiment, the catalyst ( 11 g) was loaded into a flow-type stainless steel cell that can also be used as a static cell with all valves closed. The sample was heated at $450{ }^{\circ} \mathrm{C}(5$ ${ }^{\circ} \mathrm{C} / \mathrm{min}$ ramping) under He for $3 \mathrm{~h}$ to remove any remaining trace water before the experiment. Then $20 \mathrm{mmol}$ GVL was injected into the cell at $135^{\circ} \mathrm{C}$. Before the data collection, the cell was flushed using dry He to remove weakly bound GVL molecules. The samples were cooled to $<15 \mathrm{~K}$ during data collection. After each reaction, the cell was flushed with dry He, sealed and cooled for INS collection to detect the presence of possible reaction intermediates. INS spectra of pure solid compounds for both starting material and reaction products were collected at $5 \mathrm{~K}$. The methods of DFT calculations and modelling of the INS spectra were shown in Supplementary Methods DFT calculations and modelling of the INS spectra. 
Data availability. All relevant data are available from the authors, and/or are included with the manuscript.

\section{Method References:}

43.Zhang, Y. et al. Mesoporous niobium phosphate : an excellent solid acid for the dehydration of fructose to 5hydroxymethylfurfural in water. Catal. Sci. Technol. 2, 2485-2491 (2012).

44.Thompson, S. P. et al. Beamline I11 at Diamond: a new instrument for high resolution powder diffraction. Rev. Sci. Instrum. 80, 075107 (2009).

Author Information: The crystal structures are available free of charge from the Cambridge Crystallographic Data Centre under reference number CCDC-1888752-1888753 and CCDC-1889968-1889969. Reprints and permissions information is available at www.nature.com/reprints. The authors declare no competing financial interests. Correspondence and requests for materials should be addressed to S.Y. (Sihai.Yang@manchester.ac.uk).

Competing interests: S.Y. and L.L. are inventors of a patent based upon this work. 
Figures and Tables:
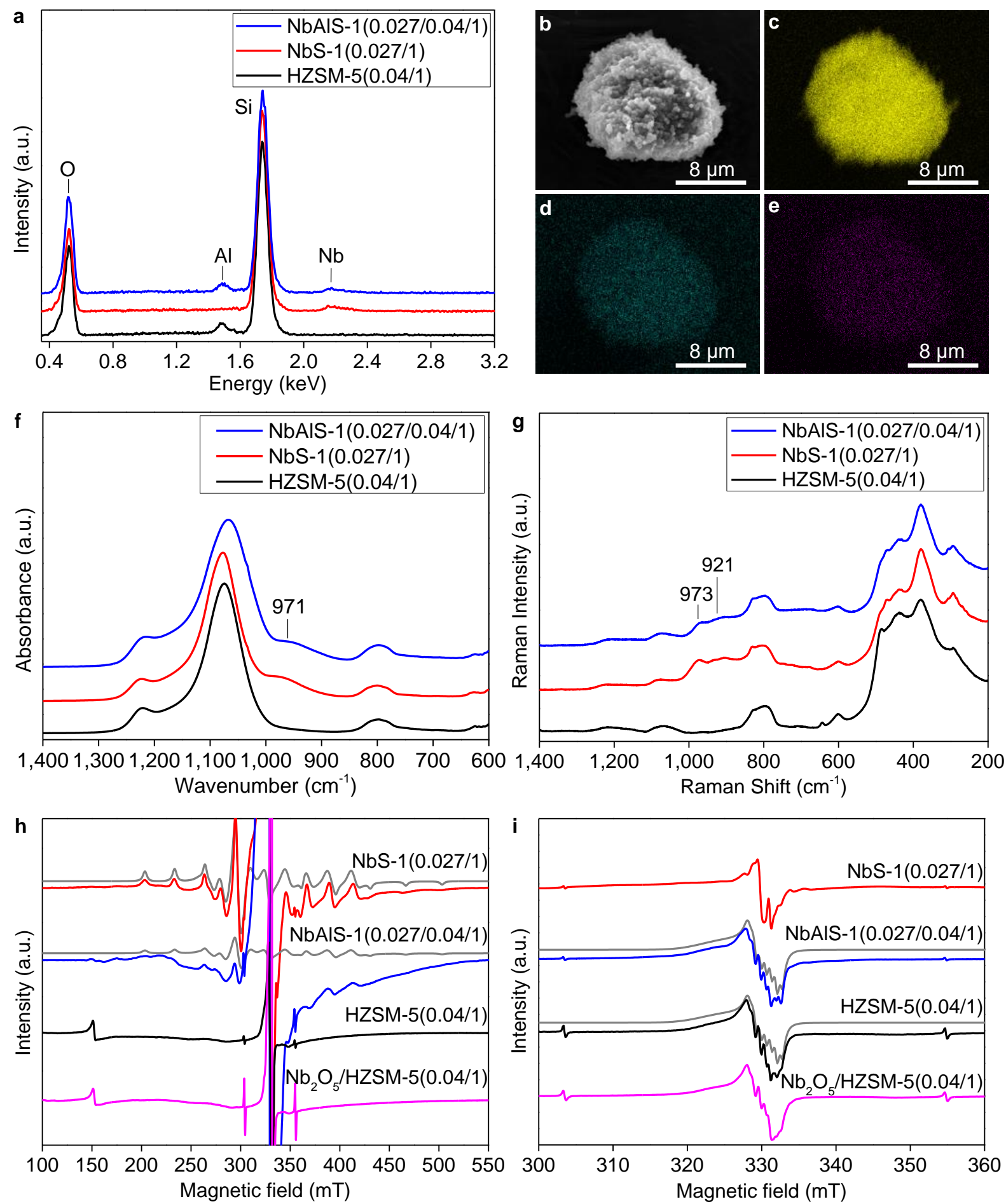

Fig. 1. Physical characterisation of catalysts. (a) EDX spectra of HZSM-5(0.04/1), NbS-1(0.027/1) and NbAlS1(0.027/0.04/1), (b) SEM image of NbAlS-1(0.027/0.04/1), EDX map of Si K $\mathrm{a}_{\mathbf{c}}(\mathbf{c}), \mathrm{Al} \mathrm{K}_{\mathrm{a}}(\mathbf{d})$ and Nb L $(\mathbf{e})$ in NbAlS$1(0.027 / 0.04 / 1)$. The peaks in regions of $0.52,1.49,1.74$ and $2.17 \mathrm{keV}$ are related to the binding energies of $\mathrm{O} \mathrm{Ka}, \mathrm{Al}$ $\mathrm{Ka}, \mathrm{Si} \mathrm{Ka}$ and $\mathrm{Nb}$ La, respectively. (f) FTIR and (g) Raman spectra of HZSM-5(0.04/1), NbS-1(0.027/1) and NbAlS1(0.027/0.04/1) samples. X-band (ca. $9 \mathrm{GHz})$ EPR spectra of activated zeolites by $\gamma$-irradiation at $77 \mathrm{~K}$ : (h) wide magnetic field-sweep, highlighting the induced $\mathrm{Nb}(\mathrm{IV})$ signals in $\mathrm{NbS}-1(0.027 / 1)$ and NbAlS-1(0.027/0.04/1) and; (i) narrow magnetic field-sweep, highlighting the induced electron hole defect Al-O ${ }^{\circ}-\mathrm{Si}$ signals in NbAlS-1(0.027/0.04/1) and HZSM-5(0.04/1). The weak features at ca. 304 and $356 \mathrm{mT}$ in (i) are due to radiation induced trapped $\mathrm{H}$ atoms. Experimental spectra are shown in black, red, blue and magenta. Simulated spectra of $\mathrm{Nb}(\mathrm{IV})$ (h) and Al-O $\mathrm{O}^{-} \mathrm{Si}$ defects (i) are shown in grey. 

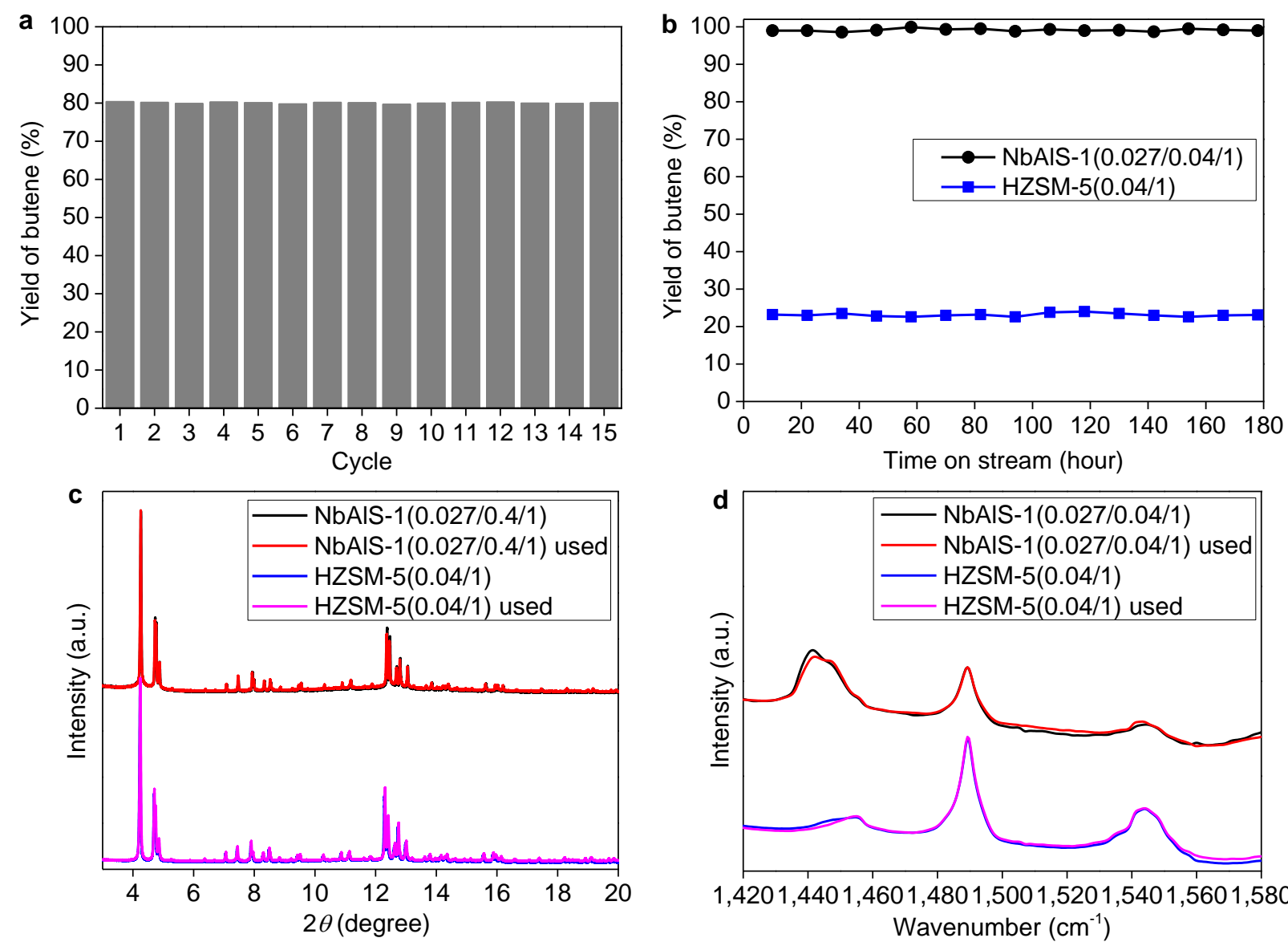

Fig. 2. Catalysts stability. (a) Comparison of butene yield over 15 cycles of reactions over NbAlS-1(0.027/0.04/1) at $320{ }^{\circ} \mathrm{C}$ using bulk GVL (99\%) as the feed. After each cycle, the catalyst is calcined at $550{ }^{\circ} \mathrm{C}$ under an air flow. (b) Lifetime study of NbAlS-1(0.027/0.04/1) and HZSM-5(0.04/1) at $320^{\circ} \mathrm{C}$ using $30 \mathrm{wt} \% \mathrm{GVL}$ in aqueous solution as the feed. The yield of butene remained at $>99 \%$ after 180 hours of continuous reaction. Comparison of (c) SXPD patterns $[\lambda=0.82487(1) \AA]$ and $(\mathbf{d})$ acidities determined by pyridine-IR of HZSM-5(0.04/1) and NbAlS-1 $(0.027 / 0.04 / 1)$ before and after the conversion of $30 \mathrm{wt} \% \mathrm{GVL}$ at $320^{\circ} \mathrm{C}$ for $180 \mathrm{~h}$. 

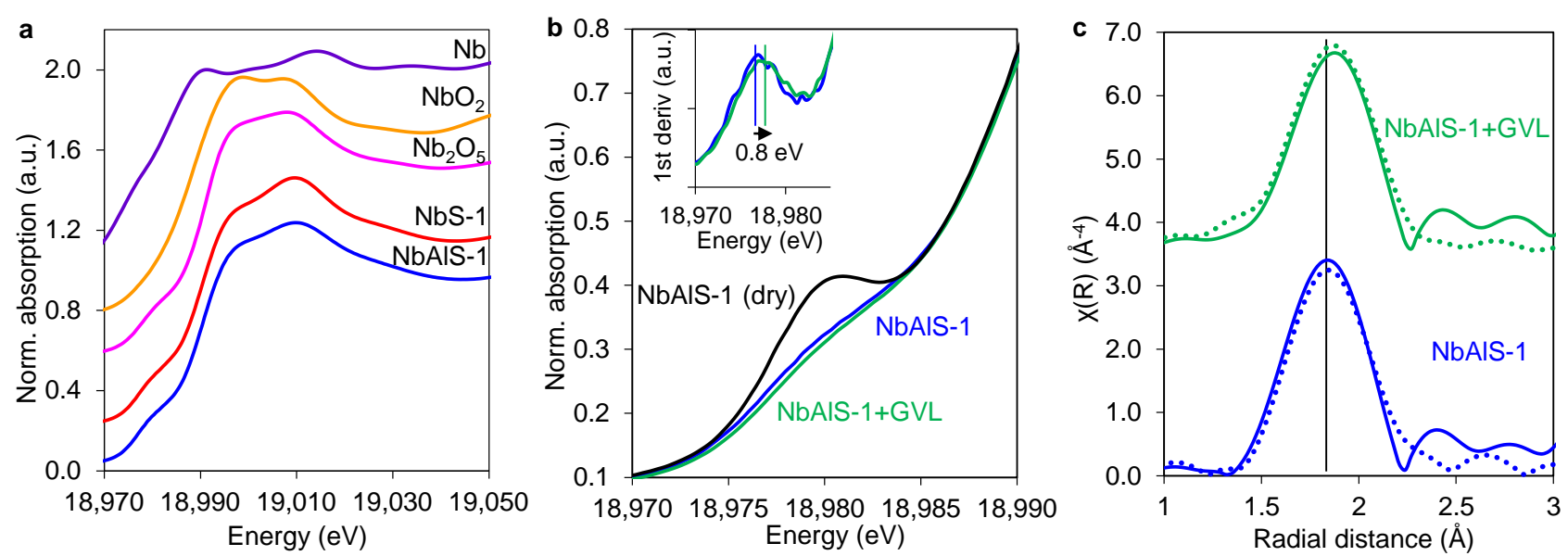

Fig. 3. Nb K-edge X-ray absorption spectroscopy (XAS) for Nb-containing zeolites. (a) XANES spectra highlighting both edge position and pre-edge feature of the Nb-containing samples. (b) Shifts of pre-edge feature in NbAlS-1, with inset showing the $1^{\text {st }}$ derivate in the presence of water and GVL substrates. (c) Phase-corrected, k3weighted Fourier transform of the EXAFS spectra and fitting curves (dot line) for NbAlS-1 as-prepared and saturated in GVL. 

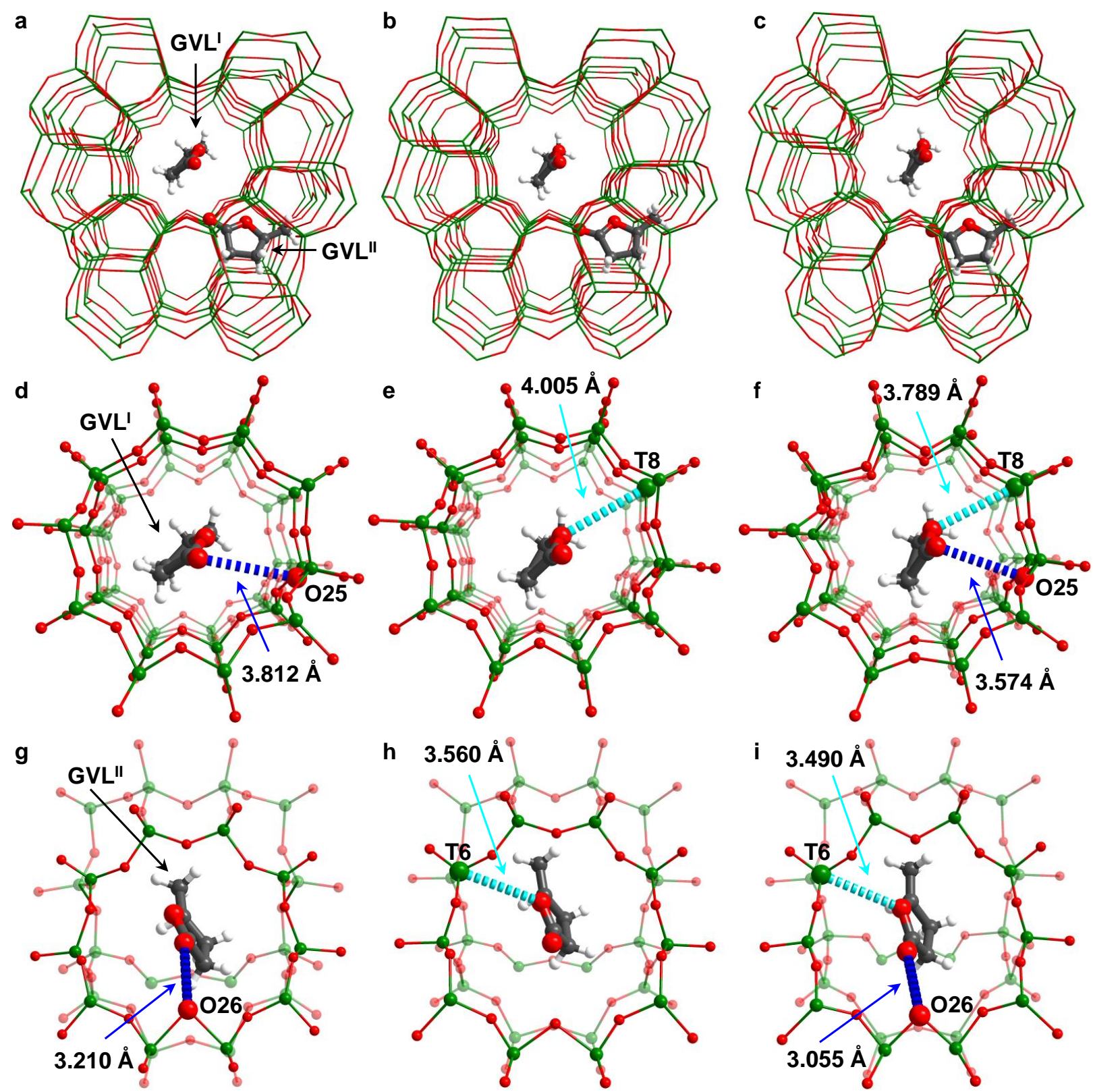

Fig. 4. Views of crystal structures of GVL-loaded HZSM-5(0.04/1), NbS-1(0.027/1) and NbAlS-1(0.027/0.04/1). All models were obtained from Rietveld refinements based upon in situ synchrotron X-ray powder diffraction data. Two distinct binding sites for GVL have been observed in the straight channel (I) and the sinusoidal channel (II). (a) HZSM5(0.04/1) $\cdot 8 \mathrm{GVL}\left(\mathrm{Al}_{3.692} \mathrm{Si}_{92.308} \mathrm{O}_{192} \cdot 8 \mathrm{C}_{5} \mathrm{H}_{8} \mathrm{O}_{2}\right)$, (b) $\mathrm{NbS}-1(0.027 / 1) \cdot 8 \mathrm{GVL}\left(\mathrm{Nb}_{2.524} \mathrm{Si}_{93.476} \mathrm{O}_{192} \cdot 8 \mathrm{C}_{5} \mathrm{H}_{8} \mathrm{O}_{2}\right)$, (c) $\mathrm{NbAlS}$ $1(0.027 / 0.04 / 1) \cdot 8 \mathrm{GVL}\left(\mathrm{Al}_{3.599} \mathrm{Nb}_{2.429} \mathrm{Si}_{89.972} \mathrm{O}_{192} \cdot 8 \mathrm{C}_{5} \mathrm{H}_{8} \mathrm{O}_{2}\right)$. The details of the host-guest binding are enlarged in $\mathbf{d}-\mathbf{i}$. Detailed views of GVL ${ }^{\mathrm{I}}$ (d,e,f) and GVL ${ }^{\mathrm{II}}$ (g,h,i) in HZSM-5(0.04/1), NbS-1(0.027/1) and NbAlS-1(0.027/0.04/1), respectively. GVL molecules and the functional sites involved in the cooperative binding are highlighted by the use of an amplified ball-and-stick model $(\mathrm{Nb} / \mathrm{Al} / \mathrm{Si}$, green; $\mathrm{C}$, grey; $\mathrm{O}$, red; $\mathrm{H}$, white). The $\mathrm{O} 1 \cdots \mathrm{Nb}$ interactions, $\mathrm{O} 2 \cdots \mathrm{O}(\mathrm{H})$ interactions are highlighted in cyan and blue, respectively. Owing to the uncertainty on locations of protons, all hydrogen bonds in this report are described as the distance between the $\mathrm{O}_{\mathrm{GVL}}$ and the $\mathrm{O}_{\text {zeolite }}$ centres. 


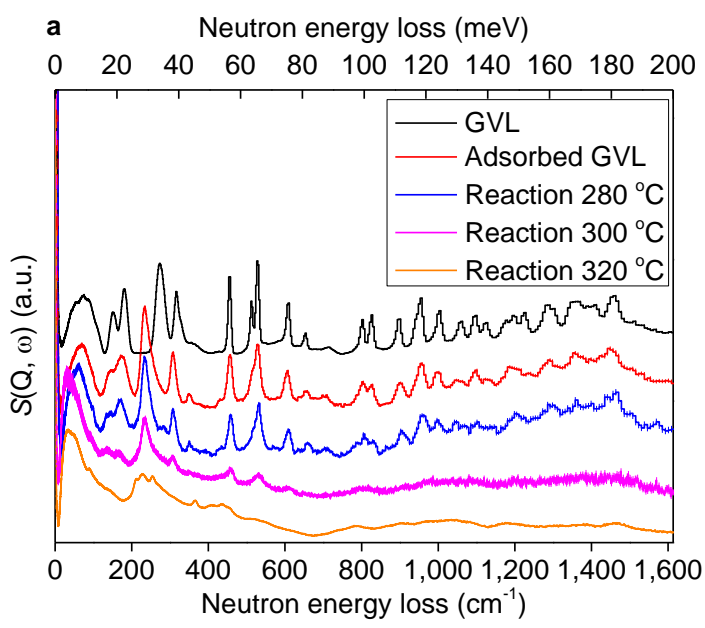

b

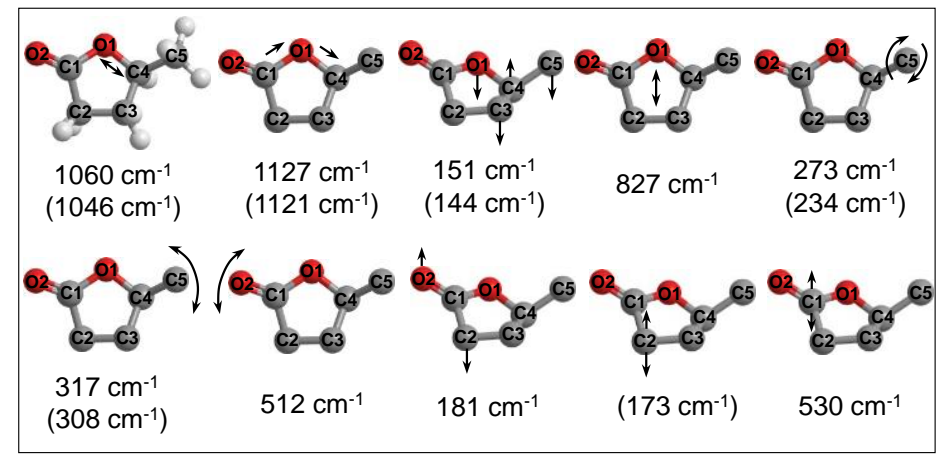

C

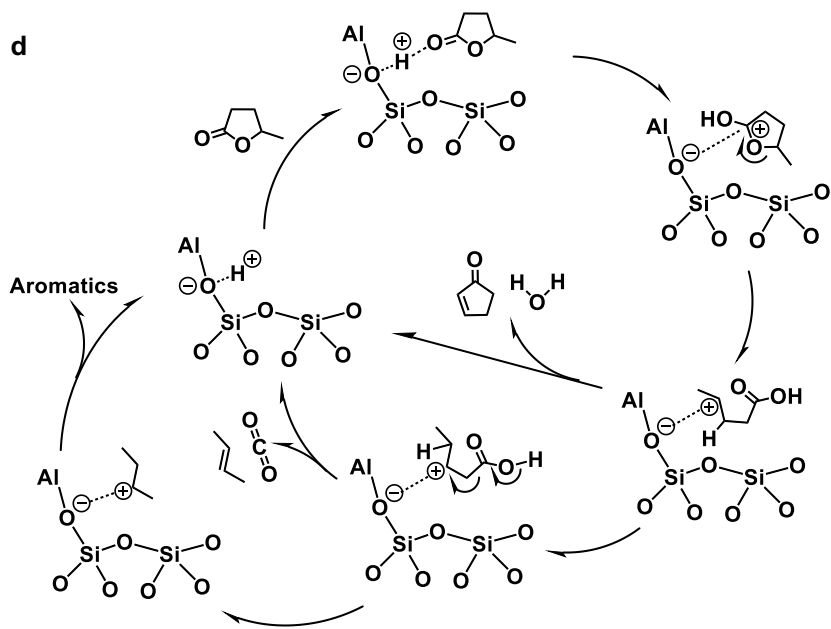

Fig. 5. Inelastic neutron scattering (INS) spectra for NbAIS-1(0.027/0.04/1) on the adsorption and catalytic conversion of GVL and proposed reaction mechanisms. All spectra shown here are after the subtraction of INS spectrum of the empty cell. No abscissa scale factor was used throughout this report for INS calculations. Where no error bars are visible these are smaller than the symbols used to represent the data points. (a) Comparison of INS spectra for condensed solid GVL, adsorbed GVL, and reacted GVL on NbAlS-1(0.027/0.04/1). (b) Selected vibrational modes of GVL. The wavenumbers of adsorbed GVL as observed by experiments are shown in parentheses. For clarification, $\mathrm{H}$ atom (white) is only displayed in the first GVL model. Proposed reaction mechanisms for the conversion of GVL over (c) NbAlS-1 based on INS/SXPD experiments and (d) HZSM-5 based on literature reports ${ }^{13,18,21}$. 
Table 1. Summary of the GVL conversion and product yields over different catalysts ${ }^{\mathrm{a}}$.

\begin{tabular}{|c|c|c|c|c|c|c|c|}
\hline \multirow{2}{*}{ Entry } & \multirow{2}{*}{ Catalyst } & \multirow{2}{*}{$\begin{array}{c}\text { GVL } \\
\text { concentration } \\
\text { (wt \%) }\end{array}$} & \multirow{2}{*}{$\begin{array}{c}\text { GVL } \\
\text { conversion } \\
(\%)\end{array}$} & \multicolumn{4}{|c|}{ Yield (mol \%) } \\
\hline & & & & Butene & 2-cyclopentenone & Aromatics & Others $^{b}$ \\
\hline 1 & HZSM-5(0.027/1) & 99 & 75 & 33.1 & 9.9 & 10.3 & 21.7 \\
\hline 2 & HZSM-5(0.04/1) & 99 & 83 & 37.9 & 11.5 & 12.4 & 21.2 \\
\hline 3 & HZSM-5(0.067/1) & 99 & 92 & 44.1 & 13.4 & 12.9 & 21.6 \\
\hline 4 & NbS-1(0.027/1) & 99 & 31 & 6.9 & 0.4 & 0 & 23.7 \\
\hline 5 & $\mathrm{NbS}-1(0.04 / 1)$ & 99 & 32 & 7.2 & 0.4 & 0 & 24.4 \\
\hline 6 & NbAlS-1(0.027/0.04/1) & 99 & 96 & 80.4 & 6.2 & 0.2 & 9.2 \\
\hline 7 & NbAlS-1(0.04/0.027/1) & 99 & 84 & 56.3 & 4 & 0.2 & 23.5 \\
\hline 8 & $\mathrm{Nb}_{2} \mathrm{O}_{5}$ & 99 & 8 & 6.9 & 0 & 0 & 1.1 \\
\hline 9 & $\mathrm{Nb}_{2} \mathrm{O}_{5} \cdot \mathrm{nH}_{2} \mathrm{O}$ & 99 & 36 & 15.8 & 0.9 & 0 & 19.3 \\
\hline 10 & $\mathrm{NbOPO}_{4}$ & 99 & 75 & 47.2 & 5.3 & 0.5 & 22.0 \\
\hline 11 & HZSM-5(0.04/1) & 60 & 81 & 29.2 & 9.3 & 9.2 & 33.3 \\
\hline 12 & NbAlS-1(0.027/0.04/1) & 60 & 100 & 92.3 & 0.3 & 0 & 7.4 \\
\hline 13 & HZSM-5(0.027/1) & 30 & 73 & 22.2 & 6.3 & 6.7 & 37.8 \\
\hline 14 & HZSM-5(0.04/1) & 30 & 76 & 23.2 & 4.7 & 7.1 & 41.0 \\
\hline 15 & HZSM-5(0.067/1) & 30 & 85 & 23.3 & 4.6 & 7.4 & 49.7 \\
\hline 16 & NbAlS-1(0.027/0.04/1) & 30 & 100 & 99.3 & 0 & 0 & 0.7 \\
\hline 17 & $\mathrm{Nb}_{2} \mathrm{O}_{5}$ & 30 & 11 & 10.1 & 0 & 0 & 0.9 \\
\hline 18 & $\mathrm{Nb}_{2} \mathrm{O}_{5} \cdot \mathrm{nH}_{2} \mathrm{O}$ & 30 & 38 & 20.0 & 2.3 & 0 & 15.7 \\
\hline 19 & $\mathrm{NbOPO}_{4}$ & 30 & 88 & 78.3 & 0 & 0 & 9.7 \\
\hline
\end{tabular}

a Reaction conditions: catalyst, $2.0 \mathrm{~g}$; reaction temperature, $320{ }^{\circ} \mathrm{C}$; atmospheric pressure; Weight Hourly Space Velocity (WHSV), $0.18 \mathrm{~h}^{-1}$; time-on-stream $=10 \mathrm{~h}$.

${ }^{\mathrm{b}}$ Other products include $\mathrm{C}_{2}-\mathrm{C}_{4}$ hydrocarbons (except butene); pentenoic acid isomers; 1-(2-methylcyclopropyl)ethanone; 3,3-diethoxy-1-propyne; cyclobutanecarboxylic acid-2-propenyl ester; 3-methyl-2-butenoic acid, cyclobutyl ester (the latter four compounds are mainly for Entries 4 and 5); 4-ethyl-4-methyl-2-cyclohexene-1-one (detected for Entries 9, 10, 18 and 19); 3-ethyl-1-isopropyl-1H-indene (detected for Entries 10 and 19) and polycyclic aromatics. 
Graphic abstract

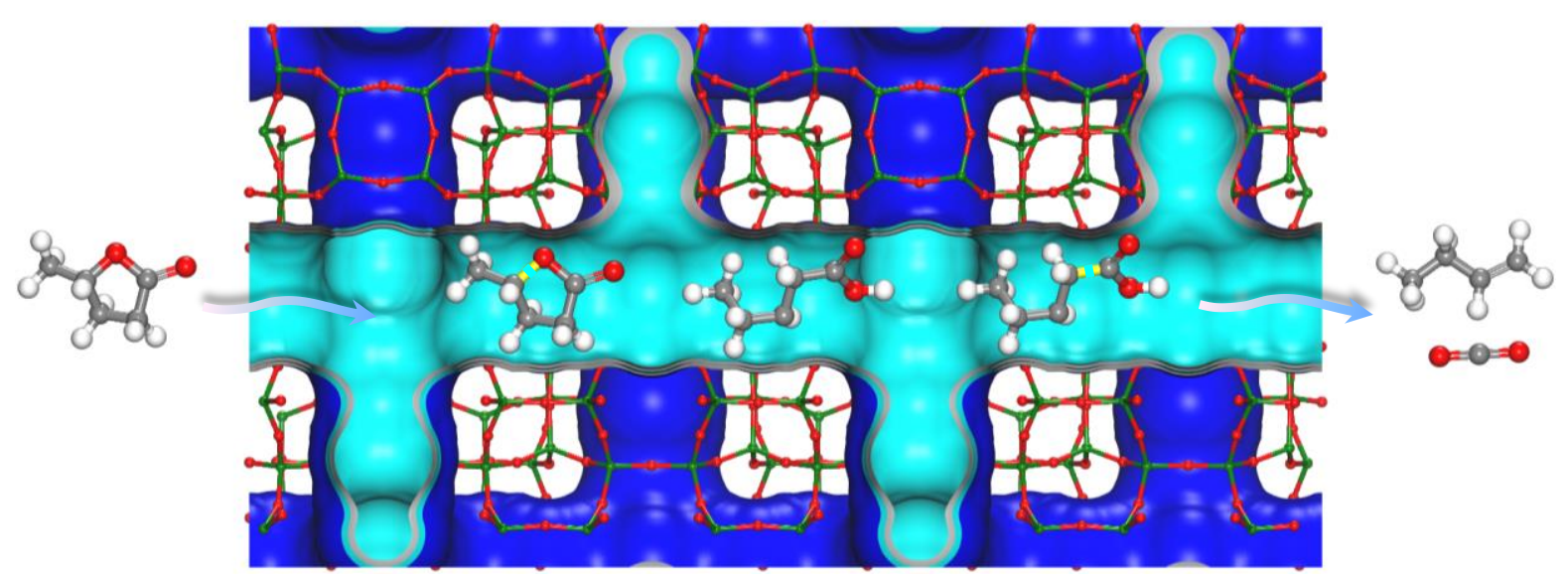

